\title{
An Un-operated d-TGA Case Holding On To Life
}

\author{
Hatice Solmaz ${ }^{1}$ \\ ${ }^{1}$ Turkiye Cumhuriyeti Saglik Bakanligi Izmir Tepecik Egitim ve Arastirma Hastanesi
}

January 29, 2021

\begin{abstract}
Complete transposition of the great arteries is incompatible with life without corrective surgery in the neonatal period. Even in the presence of large intracardiac shunts, a case of un-operated d-TGA that survived to late adulthood is thought-provoking. We described a case of un-operated d-TGA presenting at 46 years of age who had large secundum type ASD, pulmonary hypertension, pulmonary artery aneurysm, situs inversus, mirror image dextrocardia and abnormal origin of the coronary artery. The management of an un-operated case of d-TGA surviving to late adulthood has made it important to share casebased experiences as there are no evidence-based data.
\end{abstract}

\section{An Un-operated d-TGA Case Holding On To Life}

\section{Abstract}

Complete transposition of the great arteries is incompatible with life without corrective surgery in the neonatal period. Even in the presence of large intracardiac shunts, a case of un-operated d-TGA that survived to late adulthood is thought-provoking. We described a case of un-operated d-TGA presenting at 46 years of age who had large secundum type ASD, pulmonary hypertension, pulmonary artery aneurysm, situs inversus, mirror image dextrocardia and abnormal origin of the coronary artery. The management of an un-operated case of d-TGA surviving to late adulthood has made it important to share case-based experiences as there are no evidence-based data.

Key Words: complet transposition, intracardiac shunt, survived to late adulthood

\section{Case Report}

Complete transposition of the great arteries (d-TGA) is a congenital cyanotic cardiac malformation characterized by atrioventricular concordance and ventriculoarterial discordance, resulting in two parallel circuits with systemic oxygen-free blood on one side and oxygenated blood on the other (1). In order to be compatible with life, either the presence of ductus arteriosus or communication between atria or ventricles is required (1). In un-operated patients, even in the presence of atrial septal defect (ASD), the mean age of death was found to be 9 month (2). Here, we presented a case of un-operated d-TGA with a large secundum type ASD accompanied by dextrocardia, situs inversus with abnormal origin of the coronary artery, pulmonary artery (PA) aneurysm and pulmonary hypertension (PH) who survived to late adulthood, 46 year-old. To the best of our knowledge, it is the first un-operated case that survived to late adulthood in this complex anatomy.

A 46-year-old male was admitted to our outpatient clinic with complaints of shortness of breath and palpitations. He had a regular pulse of $125 / \mathrm{min}$, arterial blood pressure of 128/86 $\mathrm{mmHg}$ and respiratory rate of 19 breaths $/ \mathrm{min}$. His resting oxygen saturations were around $83 \%$ on room air and dropping to $78 \%$ with exercise. Finger clubbing, bluish discoloration on the nail bed and lips were observed.

On cardiovascular examination, the apex beat was on the right and there was a wide, fixed split second heart sound with pulmonic ejection click at the right upper parasternal border. 
His blood work showed elevated hemoglobin and hematocrit levels of $19 \%$ and $59 \% \mathrm{~g} / \mathrm{dL}$ respectively and brain natriuretic peptide level of $379 \mathrm{ng} / \mathrm{L}$.

Chest X-ray revealed presence of cardiomegaly, dextrocardia and pointed that base-apex, aortic arch and gastric air bubble was on the right (Figure-1).

Echocardiography showed mirror image dextrocardia, atrial and ventricular situs inversus, $29 \mathrm{~mm}$ ostium secundum ASD with bidirectional shunt. Tricuspid annular plane systolic excursion was normal. Moderate mitral and pulmonary valve insufficiency was observed. ASD with bidirectional shunt was confirmed by transesophageal echocardiography too (Figure-2).

CT scan demonstrated an aneurysm of the PA with a diameter of $60 \mathrm{~mm}$ (Figure-3).

In cardiac magnetic resonance imaging (CMR), aorta was arising anterior and leftward to the PA and originated from base of the right-sided hypertrophic ventricle with increased trabeculation. No contractile deficit was seen in systemic ventricle. There was aneurysmatic PA originated from the left-sided ventricle (Figure-4).

In right heart catheterization, aortic and mixed venous oxygen saturation was $85.9 \%$ and $68.2 \%$ respectively. RV end-diastolic pressure was $7 \mathrm{mmHg}$. Left heart catheterization was performed by reaching the PA through the ASD. PA oxygen saturation was 93.5\%. Mean PA and LV end-diastolic pressure was $27 \mathrm{mmHg}$ and $5 \mathrm{mmHg}$ respectively. Pulmonary vascular resistance (PVR) was not calculated because evaluation of PVR with hemodynamic and saturation data obtained by cardiac catheterization may not be reliable in d-TGA-ASD physiology. On coronary angiography, coronary artery ostia positions were mirror image of the normal orientation and coronary arteries were free from obstructions but anomalously left circumflex artery originated from the right sinus Valsalva (Figure-5).

\section{Discussion}

An un-operated d-TGA case with secundum type ASD survived to late adulthood is very rare. According to the previous data, only three cases were reported with the longest survival of un-operated d-TGA (3-5). None of these cases were accompanied by dextrocardia, situs inversus, PH, and PA aneurysm at the same time. The incidence of patients with simultaneous d-TGA, dextrocardia and situs inversus is unknown (6).

In the presence of large ASD, sufficient oxygenated blood for systemic circulation and sufficient pulmonary blood flow for pulmonary circulation are provided during ventricular diastole and systole. That is the reason why our un-operated patient survives into late adulthood. However, prolonged exposure of the pulmonary circulation to high blood pressure and oxygen-free blood flow of the systemic circulation caused PH by causing an increase in pulmonary blood flow and pulmonary vasoconstriction due to hypoxia (7). Although PA dilatation is generally seen in patients with $\mathrm{PH}$, it is rare for the PA diameter to be above $40 \mathrm{~mm}$. PA aneurysm of this width can cause life-threatening complications such as dissection, rupture or lung compression.

Another issue to be emphasized is the ability of the right ventricle (RV), which is morphologically right but functionally left, to adapt to the systemic circulation in long term. Extreme RV hypertrophy may be a response to remodeling of the RV in the systemic circulation (8). Eventually, myocardial scarring secondary to chronic cyanosis and insufficient vascular capacity not to meet the demands of the hypertrophied ventricle may contributes to ventricular dysfunction. The greatest chance of our case was that the functional insufficiency of the systemic ventricle had not developed yet and he did not experience a life-threatening arrhythmia until this age.

If d-TGA is accompanied by dextrocardia, situs inversus and abnormal origin of the coronary artery, surgery should be performed by applying a correct coronary transfer with appropriate modifications to the technique for a successful outcome in the arterial switch operation (ASO). These complex and altered anatomy can make the surgery difficult. 
We did not consider to include our patient, who lived longer than the operated patients without any corrective surgery, into a surgical process that we could not predict consequences, even if it was a transplant surgery. Because while ASO with the best long-term survival and functional outcome has a survival rate of $>95 \%$ between 15 and 25 years (9), in another study on long-term morbidity and quality of life of TGA after atrial switch surgery, the 25-year survival rate has been reported as $78 \%$. (10). We also do not have a literature support regarding the use of specific therapies for PH. We aimed to monitor our patient routinely with EKG and Holter in order to detect possible arrhythmias and follow-up with routine echocardiography to evaluate ventricular function. We preferred beta blocker, digoxin and furosemide therapy for their functional class improvement effect, heart rate and arrhythmia control. We planned to follow up the patient closely for volume status, hyperviscosity, iron deficiency and microcytosis.

Treatment strategies, complications that may develop, points to be considered in follow-up, long-term survival rates in d-TGA are determined by evaluating only patients who underwent surgical approach. Since there are no large-scale studies and evidence-based data, we believe that case-based reports will guide the follow-up and treatment of patients that survive into late adulthood without corrective surgery.

\section{Figure Legends}

Figure 1. Chest X-ray shows cardiomegaly, mirror image dextrocardia, dilated pulmonary artery, right sided gastric air bubble

Figure 2. $29 \mathrm{~mm}$ large secundum type ASD confirmed by transesophageal echocardiography

ASD, Atrial septal defect

Figure 3. CT scan demonstrating an aneurysm of the pulmonary artery

Figure 4. Cardiovascular magnetic resonance image showing transposition of the great arteries, morphologic right and functionally systemic ventricle with hypertrophic trabecular structures and morphologic left and functionally right dilated ventricle

PA, Pulmonary Artery; Ao, Aorta; LV, Left ventricle; RV, Right ventricle

Figure 5. Coronary angiography image showing LCX arises from right sinus of valsalva separately from the RCA

LCX, Left circumfarencial coronary artery; RCA, Right coronary artery

\section{References}

1. Warnes CA. Transposition of the great arteries. Circulation 2006:12:2699-709.

2. Liebman J, Cullum L, Belloc N. Natural history of transposition of the great arteries. Circulation 1969:40:237-62.

3. Oladapo OO, Ogunkunle O, Adebayo B, et al. Un-operated transposition of the great arteries in a 31-year-old Yoruba, Nigerian woman. Nigerian J Cardiol 2016:13:86-9.

4. Naganur SH, Tiwari A, Pruthvi CR. Mystery still unresolved: Untouched "Blue heart" presenting at 40yrs of age. Ann Pediatr Cardiol 2020:13:72-74.

5. Wijesekera NT, Babu-Narayan SV, Shore D, Gatzoulis MA. Mustard procedure for late natural survival with complete transposition of the great arteries and atrial septal defect. Int J Cardiol 2005:102:151-153.

6. Talwar S, Shivaprasad M, Kothari S, et al. A novel conduit-lengthening technique to facilitate the arterial switch operation. Tex Heart Inst J 2009:36:234-237.

7. Akagi S, Matsubara H, Nakamura K. Modern treatment to reduce pulmonary arterial pressure in pulmonary arterial hypertension. J Cardiol 2018:72:466-472. 
8. Hornung TS, Kilner PJ, Davlouros PA, et al. Excessive right ventricular hypertrophic response in adults with the Mustard procedure for transposition of the great arteries. Am J Cardiol 2002:90:800-3.

9. Tobler D, Williams WG, Jegatheeswaran A, et al. Cardiac outcomes in young adult survivors of the arterial switch operation for transposition of the great arteries. J Am Coll Cardiol 2010:29:58-64.

10. Görler H, Ono M, Thies A, et al. Long-term morbidity and quality of life after surgical repair of transposition of the great arteries: atrial versus arterial switch operation. Interact Cardiovasc Thorac Surg 2011:12:569-74.

\section{Hosted file}

Figure 1.pdf available at https://authorea.com/users/390916/articles/506425-an-un-operatedd-tga-case-holding-on-to-life

\section{Hosted file}

Figure 2.pdf available at https://authorea.com/users/390916/articles/506425-an-un-operatedd-tga-case-holding-on-to-life

\section{Hosted file}

Figure 3.pdf available at https://authorea.com/users/390916/articles/506425-an-un-operatedd-tga-case-holding-on-to-life

\section{Hosted file}

Figure 4.pdf available at https://authorea.com/users/390916/articles/506425-an-un-operatedd-tga-case-holding-on-to-life

\section{Hosted file}

Figure 5.pdf available at https://authorea.com/users/390916/articles/506425-an-un-operatedd-tga-case-holding-on-to-life 